\title{
Students Can Exhibit Discretionary Responding to Texts Social Media Messages During Class: Fact or Fiction?
}

\author{
Fatma Arslantas ${ }^{1}$, Eileen Wood ${ }^{1}$, Brooke Boersen ${ }^{1}$, Victoria Pulla ${ }^{1} \&$ Monika Ferrier $^{1}$ \\ ${ }^{1}$ Department of Psychology, Wilfrid Laurier University, Waterloo, Canada \\ Correspondence: Fatma Arslantas, Department of Psychology, Wilfrid Laurier University, Waterloo, ON., N2L 3C5, \\ Canada. E-mail: ars12380@mylaurier.ca
}

Received: July 7, 2019

doi:10.5430/ijhe.v8n5p157
Accepted: August 22, 2019

Online Published: August 24, 2019

\begin{abstract}
Terms such as 'compulsion' and 'addiction' are often used when describing young adults' response behaviors regarding texts and messages. Purpose of the Research: The present study documents response patterns for texts and messages in a higher education classroom context. Both the number of texts and messages responded to and the time taken between receipt and response were examined. These measures, as well as perceptions about multitasking and learning, were examined with respect to performance for lecture content. Students were assigned to either a texting or social media message condition. Within each of these conditions, students were either instructed to respond to texts/messages immediately or at their own discretion. Principal Results: Consistent with characterizations of habits/compulsions, the majority of participants in all conditions responded to most of the individual texts/messages. In no condition did all participants respond to all of the texts/messages. Students in the discretionary texting condition took longer to reply to texts/messages than those in the immediate social media condition for the vast majority of texts/messages received. Higher performance scores were found for test items not associated with the arrival of texts/messages. Students acknowledged some potential for multitasking to impact learning, however, these perceptions were not related to the volume or timing of text/message responses. Major Conclusions: This study identifies that students responding to texts/messages in the educational context is more complex than a simple habitual behaviour and that the pervasiveness may make the behavior a challenge even in live lecture contexts.
\end{abstract}

Keywords: messaging, texting, technology, learning, multitasking in the classroom, higher education

\section{Introduction}

Mobile technologies and their accompanying social media platforms, especially texting and messaging, are a ubiquitous part of the everyday social lives of students and faculty on college and university campuses around the world. Mobile technologies permit contact almost everywhere at almost any time as long as infrastructure is available to support them (Carrier, Rosen, Cheever, \& Lim, 2015). This ease in connecting with others serves an important social function on campuses by allowing students who are away from home, their family and their friends to easily maintain contact (e.g., Chen \& Katz, 2009; Madge, Meek, Wellens, \& Hooley, 2009; Palmer, Boniek, Turner, \& Lovell, 2014; Yang, 2018). In addition, enhanced connectedness can also facilitate the development of new relationships and can play a role in progressing academic goals through connections with study partners (e.g., Lampe, Wohn, Vitak, Ellison, \& Wash, 2011; Madge et al., 2009).

Being 'connected' has inherent social responsibilities. To be part of an expanded social world necessitates that students be available and participate in interactions. Specifically, when senders initiate contact it is expected that recipients will respond. These social expectations may conflict with the learning demands of higher education classrooms. To meet the social expectations, students may perceive the need to have their devices on and readily available during classes as well as being vigilant in checking and responding to messages received (Courage, Bakhtiar, Fitzpatrick, Kenny, \& Brandeau, 2015; Rosen, Carrier, \& Cheever, 2013). These behaviours can distract students from lectures, group work, and other in-class task demands (Courage et al., 2015; Wood, Mirza, \& Shaw, 2018). It is not surprising, therefore, that concerns have arisen when mobile devices are present in the classroom and why both instructors and students feel the strain of that presence, albeit from differing demands and perspectives. Although research has identified that students feel pressures to text/message in general, and that texting/messaging during traditional in-person classes can negatively impact performance, we do not know how students handle the 
competing social and learning demands when receiving texts/messages during live classes. The present study explores students' responsiveness to texting/messaging in a live classroom context.

\subsection{Literature Review: Students' Use of Mobile Media in the Classroom}

The presence of mobile technologies, especially cellphones, has reached the saturation point in many societies world-wide (Bayer, Campbell, \& Ling, 2016). Texting/messaging behaviours have been depicted as an "addiction", "compulsion" and a need to "text now" (Atchley \& Warden, 2012; Perry \& Lee, 2007; Roberts, Yaya, \& Manolis, 2014). Today's students often feel the need to regularly check and engage in social media in order to avoid being 'left out' (Carrier et al., 2015; Carrier Cheever, Rosen, Benitez, \& Chang, 2009; Terry, Mishra, \& Roseth, 2016; Tindell \& Bohlander, 2012). "Habits" evolve whereby students constantly check for messages (Bayer et al., 2016). Checking behaviours and decisions to attend to incoming messages are influenced by both external factors and internal factors (Adler \& Benbunan-Fich, 2013; Tindell \& Bohlander, 2012). For example, cell phones, are often programmed to vibrate, ring or sound a tone, or 'light up' to indicate a new text message, social media update, or incoming phone call (Carrier et al., 2015). These alerts may encourage students to shift attention away from the learning task (Wood et al., 2018). In addition to these direct cues to engage with the technology, external social cues such as viewing others engaged in texting, viewing messages or using their phones may also serve as a cue to attend to messages (Finkel \& Kruger, 2012). Internal factors related to students understanding of social expectations also may compel students to acknowledge and respond to messages received (Bayer et al., 2016). Students are aware of negative consequences including being socially disconnected or 'left out' that may follow from failing to respond to messages (e.g., Carrier et al., 2015; Ling, 2012). Today's students, therefore, often feel the need to regularly check and engage in texting/messaging to ensure their "connectedness" and availability to others (Bayer et al., 2016; Carrier et al., 2015; Carrier et al., 2009; Terry et al., 2016; Tindell \& Bohlander, 2012). In this situation, the social 'need' to engage in texting/messaging may encourage task-switching or multitasking behaviours that may distract students from the learning context.

\subsection{Texting/Messaging as a Distraction from Learning}

Multitasking involves engaging in one or more activities at the same time. Media multitasking (Carrier et al., 2015; Wang \& Tchernev, 2012; Wood et al., 2012) occurs when use of digital technologies is the focus of at least one of the tasks involved, such as using laptops to take notes, or search for information online, and often relates to contexts where users switch attention among digital media (e.g., from laptops to cell phones). In many cases media multitasking can facilitate learning, for example, when a student searches for a definition using one media device while constructing notes on another. However, recent research has identified off-task media multitasking as having a particularly negative impact in educational contexts. Off-task media multitasking occurs when students engage in task irrelevant use of digital technologies, for example, when students engage in texting/messaging exchanges that are not related to the goals of the lesson (e.g., Carter, Greenberg, \& Walker, 2017; Sana, Weston, \& Cepeda, 2013; Wood et al., 2018). Outcomes associated with off-task multitasking include loss of attention and learning decrements (Carrier et al., 2015; Junco \& Cotton, 2011; Lau, 2017; Rosen, Carrier, \& Cheever, 2013, Wood et al., 2012).

\section{The Present Study}

As advanced and strategic learners, it might be expected that students in higher education contexts have adopted and employ strategic responding behaviours to best satisfy the competing social demands of texting and the learning demands in the classroom. To understand the impact of students' responding behavior on learning, the present study extends previous research by directly examining whether students choose to respond immediately to texts/messages and whether learning decrements are related to the immediacy with which students respond to texts/messages. Specifically, students in the present study will either be required to respond immediately to texts/messages or will have the choice about when they respond to texts/messages. This will allow us to understand whether students respond compulsively to texts/messages, as suggested by earlier research (Atchley \& Warden, 2012; Perry \& Lee, 2007; Roberts et al., 2014), or if students elect to defer responding to better allow them to fully engage in the learning context.

Students' perceptions regarding the impact of multitasking also may influence students' decisions to engage in texting during ongoing classes. Early research suggested that students not only believed that they were capable of multitasking but they also believed that multitasking would not negatively impact their academic performance (Hammer et al., 2010). More recent research suggests that students demonstrate awareness that use of cellphones relative to other mobile devices such as laptops and tablets is more likely to negatively impact learning outcomes (e.g., Wood et al., 2018). The present study examines students' responsiveness to texts and messages as a function of students' beliefs about the impact of multitasking on learning. 
Finally, the present study examines responsiveness and learning across social media platforms to determine whether platform type influences student behaviour. Specifically, in the present study, phone texting is contrasted with Social media messaging. Previous literature has demonstrated inconsistent differences in learning outcomes as a function of multitasking with different media and platforms (Wood et al., 2012). Although these outcomes compared different activities (e.g., texting versus looking at profiles), the inconsistencies across platforms warrant consideration. The present study examines two platforms which allow individuals to send and receive messages.

In summary, the present study examines both the volume and timing of students' responses to external texting/messaging cues during a live lecture. Based on previous research, three hypotheses were expected. In addition, the design allows for an exploration of two exploratory research questions regarding responding to texts/messages during lectures.

\subsection{Hypotheses}

1. Students will indicate comfort with social media and associated technologies.

2. The perceived capability of multitasking will be associated with lower impact of multitasking on learning.

3. Students will respond to messages when prompted while using either social media or text messaging.

\subsection{Exploratory Research Questions}

1. Are there differences in the response patterns/speed of responding for students using social media versus texting?

2. Do students respond at different rates when instructed to answer immediately to tests/messages versus having the discretion to answer at their own pace?

\section{Method}

\subsection{Participants}

A sample of 246 undergraduate students (female $=176$, male $=70, M_{\text {age }}=18.19, S D=1.36$, age range $=17-32$ ) were recruited through a research participation program from a mid-sized Canadian university. There were no age differences as a function of gender $\left(M_{\text {Female age }}=18.15, S D=1.54 ; M_{\text {Male age }}=18.29, S D=0.788 ; t(243)=-0.73, p=\right.$ 0.47). Overall, most participants described themselves as Caucasian (52.2\%), followed by Mixed Origin (13.5\%), South Asian (12.0\%), East Asian (7.6\%), African American (2.8\%), Southeast Asian (1.6\%), Middle Eastern (1.2\%), Latin American (1.6\%), and 'other' (7.6\%). Participants earned three credits towards their course grade for participation in this lab-based live lecture. This study was reviewed and approved by a university research ethics board and all participants were treated in accordance with APA ethical guidelines.

Participants were randomly assigned to one of two platforms: social media (i.e., where participants responded to messages sent using Facebook ${ }^{\mathrm{TM}}$ ) and texting. Within each of these two platform conditions, half of the participants were instructed to immediately respond to texts and messages received and half were instructed that they could use their discretion and respond as they typically would respond texts/messages.

\subsection{Materials}

The materials used in this study comprised of a 40-minute instructional lecture, a set of 10 text and social media texts/messages, one quiz, and one online survey.

\subsubsection{Lecture}

One 40-minute lecture on classical conditioning was presented by an experienced Psychology professor to each group of participants. The lecture used 31 PowerPoint slides and was scripted to be consistent across presentations.

\subsubsection{Texts/messages}

Ten scripted texting/social media messages were delivered by research assistants to designated participants at the onset of slide two and every third slide thereafter. Timing for each message sent and received was recorded. Messages varied with some being relevant to the material (e.g., "what is a conditioned response?") and some being social (e.g., "do you have any fun plans for the summer?") ${ }^{1}$. Participants were instructed to interact only with research assistants during the lecture.

\subsubsection{Post-lecture Content Quiz}

All participants completed a 20-item multiple choice content quiz following the lecture. Questions reflected those 
used in ongoing classes for students in first year courses. Thirteen items corresponded to content where texts/messages were sent to participants during the lecture and seven items reflected content where no texts/messages were presented.

\subsubsection{Survey}

An online pre-lecture survey assessed demographic information (i.e., age, gender, and ethnicity), and students' ease and comfort with technologies. Ease with technologies was assessed through one question employing a 5-point Likert-type scale (anchors 1 = "very uncomfortable" to 5 = "very comfortable"). Perceived comfort with Facebook and cellphones were each assessed through Likert-type scales (anchors $1=$ "very uncomfortable" to 5 = "very comfortable" with a sixth option indicating that the technology was not used). Following the lecture, students answered two questions regarding their ability to multitask and their perceptions regarding the impact of multitasking on learning. Both questions employed a 5-point Likert type scale, with ability to multitask ranging from $1=$ "not at all capable" to $5=$ "very capable" and impact of multitasking on learning ranging from $1=$ "not at all" to $5=$ "very much". Finally, students were asked to rate the similarity of the experimental session with typical learning contexts using a 5-point Likert type scale ranging from $1=$ "not at all similar" to 5 = "very similar".

\subsection{Procedure}

Students were instructed to bring their own technologies to the study. Lectures were held in classrooms that accommodated 20 to 40 students. The online survey was completed at the beginning of the testing session prior to the lecture. Students were randomly assigned to conditions prior to each session and participants were provided with verbal and written instructions specific to their assigned condition after completing the survey. Participants in the texting conditions were asked to provide their cell-phone numbers to a research assistant. Participants assigned to the social media conditions were asked to provide their Facebook ${ }^{\mathrm{TM}}$ usernames. Throughout the lecture, research assistants provided texts/messages to each participant. In general, the ratio was one research assistant assigned to four participants all in the same condition (i.e., texting or social media). Research assistants were located out of view of participants either at the back of the classroom or in the hallway during the lecture. Texts/messages (texting or social media messages) were delivered at set-intervals that coincided with 10 designated slides that appeared at approximately the same time in every presentation. The participants were instructed to answer all 10 messages before the end of the lecture, however rates of responding to each message were specified by condition. Specifically, half of the participants in each condition were instructed to answer the texts/messages immediately after receiving them, while the other half of the students had the discretion to answer the texts/messages at the rate they would normally respond.

\section{Results}

\subsection{Student Perceptions}

\subsubsection{Ease and comfort with technology}

Overall means indicated high levels of ease with technology in general $(M=4.34, S D=0.68$; approaching "very easy" on the 5 item scale), comfort with cellphones $(M=4.76, S D=0.48$; approaching "very comfortable" on the 5 -item scale), and comfort using Facebook ${ }^{\mathrm{TM}}(M=4.44, S D=0.81$; approaching "very comfortable"). Three ONEWAY ANOVAs (conducted using SPSS version 20) comparing mean scores across conditions yielded no significant differences for any of these three variables.

\subsubsection{Perceptions about multitasking}

Overall mean ratings of students' perceived ability to multitask fell at the midpoint of the scale $(M=3.04, S D=0.88)$ indicating "somewhat capable" of multitasking. Overall mean ratings reflecting students' perceptions regarding the impact of multitasking on learning was just above the midpoint of the scale $(M=3.66, S D=0.83)$ indicating "quite a lot" of impact. Two ONEWAY ANOVAs were conducted to assess potential differences in ratings as a function of condition. No significant differences in mean ratings were found among the four conditions. A significant negative correlation, $r(245)=-.44, \mathrm{p}<.001$ indicated that higher levels of perceived ability to multitask were associated with lower perceived impact on learning.

\subsubsection{Session similarity to typical learning}

Students responded to one question asking them to rate the similarity of the testing session to a typical class. Overall, mean ratings fell just above the midpoint of the scale indicating more than "somewhat similar" to typical learning $(M$ $=2.84, S D=1.04)$. Comparisons among the conditions using a ONEWAY ANOVA yielded no significant differences among four conditions. 


\subsection{Performance Measures}

Two aggregated proportional scores were calculated for the multiple choice test. The first aggregated proportional score reflected performance for the 13 items corresponding to the texts/messages sent to participants during the lecture (overall $M=0.60, S D=0.19$ ). The second proportional score reflected the seven items where participants were not prompted through texts/messages (overall $M=0.65, S D=0.20$ ). A 4 (condition) by 2 (performance test score) mixed model ANOVA was conducted to assess differences among the conditions for the two proportional scores. A significant main effect was found for type of proportional score, indicating higher scores for items not associated with texts/messages than those associated with texts/messages, $F(1,242)=13.52, p<.001)$. There was no main effect for condition, nor was the interaction significant.

\subsection{Perceptions and Performance: Regressions}

Two linear regressions were conducted to assess perceptions regarding both the impact of multitasking on learning and multitasking capability on each of the proportional test scores. The overall model was significant $\left(R^{2}=.04, F(2\right.$, $242)=5.21, p=.01)$ for the model assessing performance when texts/messages were present. Only the perceived impact of multitasking on learning was significantly associated with test performance, $\beta=-.04, t(242)=-2.21, p$ $=.03$. Specifically, higher perceptions regarding the negative impact of multitasking were associated with lower test performance scores. The overall model was not significant for items where no texts/messages were presented.

\subsection{Responding to Texts/Messages}

A count was conducted to determine how many participants in each condition responded to each of the ten texts/messages sent by research assistants. As summarized in Table 1, overall the majority of participants responded to each of the individual texts/messages in each condition. However, in no condition did all participants respond to all texts/messages. In social media and texting conditions where participants were instructed to reply immediately to texts/messages, approximately half of the participants $(n=29)$ responded to all texts/messages. In conditions where participants elected when and if they should respond to texts/messages, only 22 participants in the social media condition and 18 participants in the texting condition responded to all texts/messages. A chi-square analysis conducted to determine whether the number of participants completing all texts/messages differed across conditions was not significant, $\chi^{2}(3)=4.69, p=$ n.s. An ANOVA conducted to assess average number of responses per group was also not significant.

Table 1. Number of participants responding to each of the ten texts/messages as a function of condition

\begin{tabular}{|c|c|c|c|c|c|c|c|c|c|c|c|}
\hline \multirow[b]{2}{*}{ Condition } & \multicolumn{11}{|c|}{ Text/message Number } \\
\hline & 1 & 2 & 3 & 4 & 5 & 6 & 7 & 8 & 9 & 10 & $\begin{array}{l}\text { Responded to } \\
\text { all } \\
\text { text/messages }\end{array}$ \\
\hline $\begin{array}{l}\text { Social media } \\
\text { Immediate } \\
(n=63)\end{array}$ & 44 & 60 & 56 & 58 & 57 & 57 & 55 & 58 & 61 & 53 & 29 \\
\hline $\begin{array}{c}\text { Social media } \\
\text { Discretionary } \\
\quad(n=60)\end{array}$ & 43 & 56 & 45 & 51 & 54 & 57 & 57 & 56 & 57 & 47 & 22 \\
\hline $\begin{array}{l}\text { Texting } \\
\text { Immediate } \\
(\mathrm{n}=63)\end{array}$ & 44 & 58 & 50 & 59 & 54 & 55 & 57 & 60 & 59 & 49 & 29 \\
\hline $\begin{array}{c}\text { Texting } \\
\text { Discretionary } \\
(\mathrm{n}=60)\end{array}$ & 38 & 57 & 42 & 50 & 55 & 56 & 50 & 56 & 55 & 47 & 18 \\
\hline
\end{tabular}

\subsection{Response Time to Texts/Messages}

On average, participants in the social media conditions responded to texts/messages in 1.93 minutes while those in the texting conditions responded in 2.05 minutes. The average response times for participants instructed to respond immediately to the texts/messages ranged from 1.50 minutes to 1.69 minutes for the texting and social media conditions, respectively (see Table 2 for a complete summary). In comparison, those instructed to respond as they 
normally would had average response times ranging from 2.16 minutes to 2.61 minutes for the social media and texting conditions, respectively (see Table 2).

Table 2. Descriptive summary of time (minutes) taken to respond to each of the tent/messages as a function of condition

\begin{tabular}{|c|c|c|c|c|c|}
\hline \multicolumn{6}{|c|}{ Condition } \\
\hline $\begin{array}{c}\text { Text/ } \\
\text { message }\end{array}$ & $\begin{array}{c}\text { Social media } \\
\text { Immediate }\end{array}$ & $\begin{array}{l}\text { Social media } \\
\text { Discretionary }\end{array}$ & $\begin{array}{l}\text { Texting } \\
\text { Immediate }\end{array}$ & $\begin{array}{c}\text { Texting } \\
\text { Discretionary }\end{array}$ & $F$-values \\
\hline Сие & $M(S D)$ & $M(S D)$ & $M(S D)$ & $M(S D)$ & \\
\hline Number & $N$ & $N$ & $N$ & $N$ & \\
\hline \multirow[t]{2}{*}{1} & $1.57(1.69)$ & $2.21(2.93)$ & $2.95(3.99)$ & $3.97(4.97)$ & $F(3,165)=3.45, p=.02$ \\
\hline & 44 & 43 & 44 & 38 & \\
\hline \multirow[t]{2}{*}{2} & $1.73(1.53)$ & $2.71(2.56)$ & $1.78(2.35)$ & $3.58(4.84)$ & $F(3,227)=4.77, p=.003$ \\
\hline & 60 & 56 & 58 & 57 & \\
\hline \multirow[t]{2}{*}{3} & $2.43(3.03)$ & $3.60(2.26)$ & $1.88(2.10)$ & $5.43(4.88)$ & $F(3,189)=11.04, p<.001$ \\
\hline & 56 & 45 & 50 & 42 & \\
\hline \multirow[t]{2}{*}{4} & $1.84(2.44)$ & $2.25(1.75)$ & $1.95(1.61)$ & $3.20(3.45)$ & $F(3,214)=3.47, p=.02$ \\
\hline & 58 & 51 & 59 & 50 & \\
\hline \multirow[t]{2}{*}{5} & $1.26(1.59)$ & $1.72(2.29)$ & $1.31(1.21)$ & $2.13(2.52)$ & $F(3,216)=2.31, p=.08$ \\
\hline & 57 & 54 & 54 & 55 & \\
\hline \multirow[t]{2}{*}{6} & $1.72(1.91)$ & $2.25(2.23)$ & $1.44(1.07)$ & $2.73(3.19)$ & $F(3,221)=3.68, p=.01$ \\
\hline & 57 & 57 & 55 & 56 & \\
\hline \multirow[t]{2}{*}{7} & $1.25(1.27)$ & $1.72(1.91)$ & $1.46(1.36)$ & $2.48(3.03)$ & $F(3,215)=3.81, p=.01$ \\
\hline & 55 & 57 & 57 & 50 & \\
\hline \multirow[t]{2}{*}{8} & $1.74(1.65)$ & $2.63(1.43)$ & $2.00(1.95)$ & $3.54(2.89)$ & $F(3,226)=8.64, p<.001$ \\
\hline & 58 & 56 & 60 & 56 & \\
\hline \multirow[t]{2}{*}{9} & $2.08(1.63)$ & $3.16(2.51)$ & $2.39(1.64)$ & $3.51(2.37)$ & $F(3,228)=5.94, p=.001$ \\
\hline & 61 & 57 & 59 & 55 & \\
\hline \multirow[t]{2}{*}{10} & $2.09(1.71)$ & $2.23(1.68)$ & $1.96(1.49)$ & $2.43(1.72)$ & $F(3,192)=.70, p=.55$ \\
\hline & 53 & 47 & 49 & 47 & \\
\hline \multirow[t]{2}{*}{ Average } & $1.69(1.03)$ & $2.16(0.97)$ & $1.50(0.74)$ & $2.61(1.21)$ & $F(3,94)=5.76, p=.001$ \\
\hline & 29 & 22 & 29 & 18 & \\
\hline
\end{tabular}

Given the variability in the number of respondents for each of the texts/messages and the associated limitations in sample size overall, analyses examining differences in time taken to respond to texts/messages were conducted individually for each of the 10 texts/messages using a ONEWAY ANOVA to examine differences as a function of condition. Analyses for all but two texts/messages yielded a significant main effect for condition. Texts/messages 5 and 10 did not differ as a function of condition. Subsequent Tukey b post hoc comparisons were conducted to examine differences among the conditions for the remaining 8 texts/messages. Figure 1 summarizes the pattern of response times as a function of condition. Overall, participants in the texting condition who replied as they would normally took longer to reply to texts/messages than those in the social media condition who were asked to respond immediately for all but one slide (text/message 6 , see Table 2 for time). Those who replied as they would normally only differed as a function of platform in one case (text/message 8 ), where those in the texting condition were slower than those in the discretionary social media condition. There were no significant differences in response times between those in the texting immediate condition and those in the social media immediate condition. Participants in the immediate texting conditions responded more quickly than their peers who texted as they would normally. Comparisons among the two social media conditions yielded only one significant difference in response times. Those 
asked to respond immediately were quicker in their responses than those who responded to the texts/messages as they would normally (for text/message 9 ).

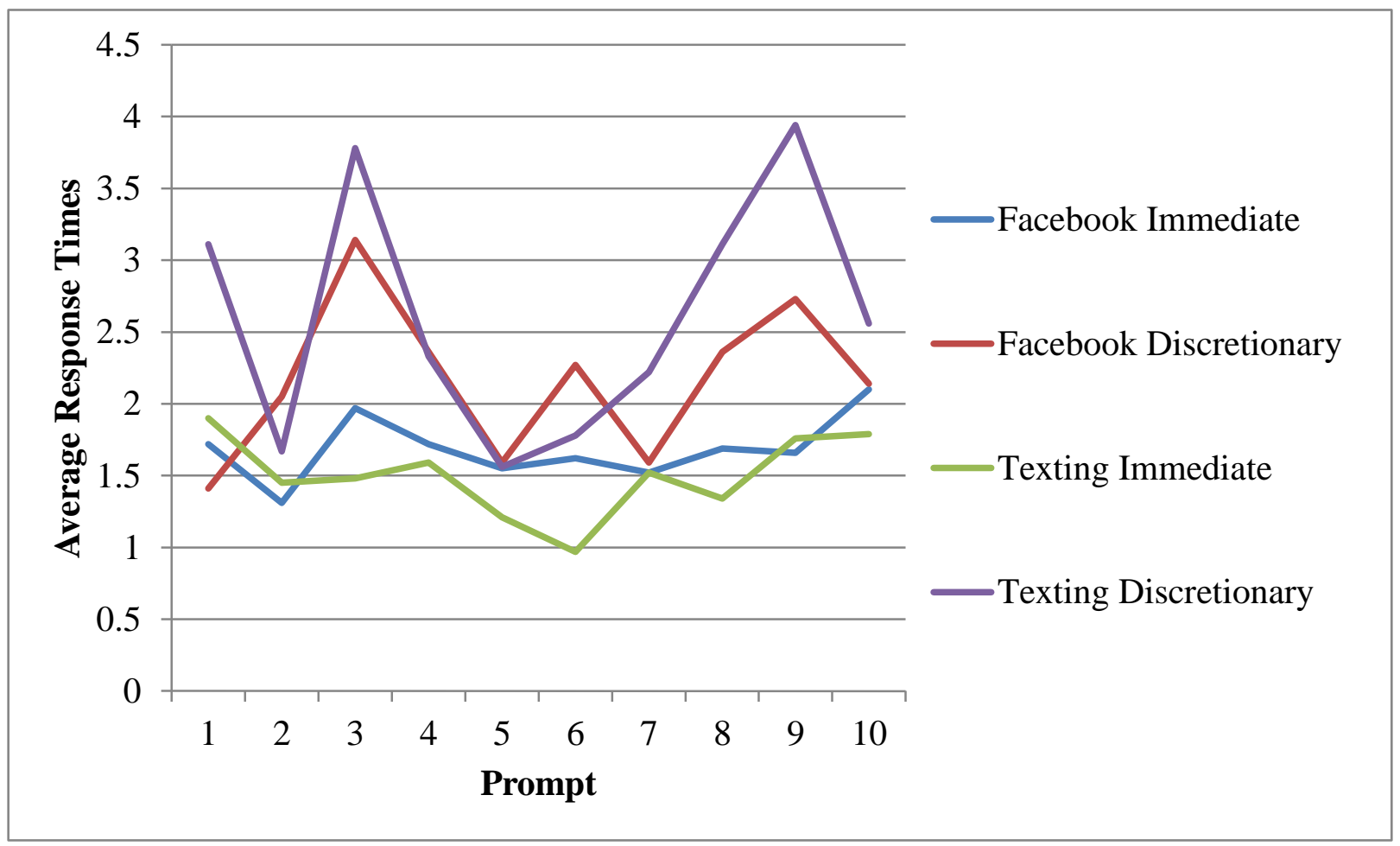

Figure 1. Response Times to Each of the Ten Text/Messages Sent As a Function of Condition.

\subsection{Impact of Response Time on Performance}

One linear regression was conducted to determine the impact of time taken to respond to texts/messages on performance on the multiple-choice test. The model was not significant.

\subsection{Perceptions and Response Time}

Three Pearson correlations were conducted to assess (a) the relationship between comfort with cell phones and average response times, (b) comfort with social media technologies and average response times, and (c) perceptions about multitasking and average response times. None of the correlations were significant.

\section{Discussion}

Considerable research indicates that the presence of mobile technologies expands and enhances our understanding of social connections and 'social space' beyond the constraints of typical face-to-face social interactions where participants share and experience the same place and time together (e.g., Bayer et al., 2016). Despite this expansion, the presence of mobile technologies in constrained face-to-face contexts such as classrooms may not be conducive or productive for student learning. The present study provided an opportunity to examine how students use mobile media to text and message when engaged in live lectures. The present study makes clear that students responding to texts/messages in the educational context is more complex than a simple habitual behaviour of immediate responding as suggested in some previous literature, but nonetheless is a challenging behaviour for learning in higher educational contexts.

Consistent with extant literature (e.g., Carrier et al., 2015; Van der Schuur, Baumgartner, Sumter, \& Valkenburg, 2015; Woodcock, Middleton, \& Nortcliffe, 2012), and our first hypothesis, students in the present study indicated near ceiling levels when asked about how easy it is to use technology in general. Similarly, they indicated near ceiling levels when asked about their comfort with the technology they used in this study (i.e., cellphones and social media). Indeed, students comfort with technologies did not impact response times to texts/messages. Also consistent with recent previous literature (e.g., Wood et al., 2018), the students in our sample were positive but cautious with respect to their perceptions about being able to multitask. Although they believed they would be "somewhat capable" of multitasking, they acknowledged that doing so would negatively impact learning. Interestingly there was a negative correlation in these perceptions, such that students who were more confident in their ability to multitask 
were associated with less concern that multitasking could negatively impact performance. This confirms an ongoing concern that some students who feel more able to multitask may persist in this behaviour even in educational contexts where it is detrimental to learning. This is a particular concern in contexts involving off-task multitasking where students are particularly likely to experience performance decrements. Together these outcomes confirm the importance of examining cellphone use in higher education classroom contexts.

\subsection{Responding to Texts/Messages}

It was expected that all students, at some point would respond to all texts and messages sent by the research assistants (Hypothesis 3). However, this was not the case. Although the majority of participants responded to each of the ten messages, in no condition did all students respond to all messages. Students demonstrated the capacity to be selective and strategic at least some of the time in terms of whether they would or would not respond to a message sent during their class. Although this suggests some inhibition in the perceived need to respond to every message received, it is important to note, that most of the time, across both types of responding (i.e., texting and messaging), as well as across instructional sets that required immediate or self-guided responding, students did respond to messages. Overall, this outcome supports previous literature indicating that, for the most part, students do feel the need to regularly check and engage in social media (Carrier, et al., 2015; Carrier, et al., 2009; Terry et al., 2016; Tindell \& Bohlander, 2012). However, there is also indication that the need to respond is not as overwhelming as might be expected, as is noted by both failures to respond to some messages and delays in responding to others.

Although we did not observe or record when students first examined incoming messages, their pattern of responding suggests that students may be actively monitoring incoming messages and making decisions regarding whether to respond or not. There were no particular messages that were uniformly dismissed by all students, indicating that it was not the message content that influenced their decision to respond or not. Instead, the individuality in the pattern of responding suggests that students may be responding to the demands of the learning context (i.e., their own needs to attend and engage in order to learn), rather than always feeling 'compelled' to engage in social media. This discretionary action, however, is limited. Students in the present study generally responded to messages in a linear fashion, meaning that responses were not "pooled" at particular intervals during the session. In addition, although the number of students who were instructed to respond to messages immediately appeared to be greater than those who had more discretion about when they could reply, the differences in numbers were not statistically significant. Thus, students, even when given discretion about when to respond, generally responded after each message was delivered, suggesting that habitual patterns or a sense of urgency accompanies the appearance of messages. This has implications for classroom instruction in terms of distractibility and potential decrements in learning.

\subsection{Response Time to Texts/Messages}

Consistent with instructions provided, it was expected that students asked to respond in their natural way to texts and messages would take longer than those asked to respond immediately. This was not supported in the findings. Instead, the most consistent difference occurred across instructions and media combined. Response times were longest for most comparisons for participants in the natural texting condition when compared to those asked to respond immediately to messages in the Social media condition. This fairly systematic difference suggests that students may not reflexively respond to texts during lectures in the same way they respond to other social media. Students seemed to be able to inhibit responding more when those messages were delivered through texts on their phone rather than social media, but only when there was a sense of immediacy for the social media context. This may be a product of accessibility. Specifically, when students had their laptop open and available during lectures, messages delivered through social media were immediately available, whereas texts delivered by phone required switching to another device, or switching between note-taking and the phone. This additional action may have accounted for some differences in time taken to respond. However, it is unlikely that this fully explains response time differences given that there were no consistent time differences between those using cell phones in their natural way and those responding to social media messages naturally. Instead this pattern of responding again suggests that when students access their text messages naturally during lectures, they may be more strategic and more likely to hold off until a better opportunity is present. Interestingly, there were no consistent differences in response times between students asked to respond to texts naturally and those asked to respond immediately. This suggests that even when asked to respond immediately, students exert some level of control over their responding to texts.

Only other small sporadic differences in response times were noted among the other conditions and these differences were not specific to any particular texts or messages. This suggests a somewhat random or individual difference across the remaining conditions. That is, differences noted did not occur at a particular point in the presentation or as 
a function of specific instructional sets. Overall, the instructions to students seem to be less predictive of outcomes than choices students make in responding.

\subsection{Impact of Response Time on Performance}

The amount of time taken to respond to texts and messages was not related to overall performance outcomes. However, greater decrements in learning were noted for lecture content items associated with a message cue versus items not associated with a message cue. This is consistent with previous literature that suggests that multitasking negatively impacts performance (e.g., Carter et al., 2017; Wood et al., 2018).

The failure to find differences between students asked to respond immediately and those asked to respond in their natural way was unexpected, as those interrupted and responding immediately were expected to experience the greatest disruption at key intervals in the lecture. However, the present findings may reflect the immediacy of checking texts/messages rather than responding per se. Perhaps all students checked incoming texts/messages as they arrived causing an equal level of disruption, regardless of response times. Future research documenting the time of 'checking' messages in addition to the response time would be an important next step to understanding why immediacy of responding did not result in differential learning decrements.

\subsection{Limitations and Future Directions}

The present study was lab-based but mirrored a real classroom context. It had a real teacher delivering a real and relevant lecture to participants in a classroom context, but it was nonetheless a lab study. It would be important to examine responding in an actual classroom, particularly those employing diverse instructional approaches that include both lecture and active participation.

Although the present study provides one of the first direct assessments of the relationship between responding to texts and messages delivered by phone or social media, an important next step would be to assess when students first look at texts/messages sent to them. The linear nature of responses and limited times to response suggest that students responded relatively quickly and individually to each incoming message. However, it would be important to assess whether there was any lag between students reading their messages and choosing to respond in order to fully understand if and when students are strategic in a classroom context.

\subsection{Closing Comments}

Most traditional on-campus classrooms are constrained in that social interactions are presumed to be bounded by the time, space, and the context of the classroom (i.e., lecture, group work), as well as the people present. Research indicates that when students are engaged in live discussion, there is less likelihood that they will be on their phones (Kruger et al., 2018). However, many in-class activities involve extended periods of time when students are not actively engaged in live conversation and, instead, are expected to be engaged in listening, not-taking and other activities. Findings from the current study suggest that texts and messages sent during this time will most likely serve as a disruptive function as students provide a response and this, in turn, could negatively impact learning outcomes, especially for the content associated with the time when the response was being sent.

Overall, it is clear that people both respond to cues to check texts and messages and then subsequently respond to the vast majority of those texts and messages. These cues function like habits and are challenging to 'turn off', even when the user is aware that responding can negatively impact performance (Bayer et al., 2016). For example, when people text and drive they are aware that it is a dangerous activity but they do it anyway (e.g., Atchley \& Warden, 2012). There are however internalized cues present in the educational context that compete with the cues to respond to distractions and that facilitate students' ability to concentrate. For example, students in higher education classrooms engage in monitoring and other metacognitive behaviours that encourage them to listen, take notes, read, summarize, question, and engage in many other learning behaviours (e.g., Schraw, Crippen, \& Hartley, 2006). The present study suggests that these classroom cues may not be sufficient to override the need to respond to texts/messages during classes. It is important for educators to be aware of these perceived demands on students within their classrooms and for researchers and educators to find mechanisms to inhibit distractive behaviours and/or decrease the detrimental impact of these behaviours on learners.

\section{References}

Adler, R. F. \& Benbunan-Fich, R. (2013). Self-interruptions in discretionary multitasking. Computers in Human Behavior, 29(4), 1441-1449. https://doi.org/10.1016/j.chb.2013.01.040

Atchley, P. \& Warden, A. C. (2012). The need of young adults to text now: Using delay discounting to assess informational choice. Journal of Applied Research in Memory and Cognition, 1(4), 229-234. 
https://doi.org/10.1016/j.jarmac.2012.09.001

Bayer, J. B., Campbell, S. W. \& Ling, R. (2016). Connection cues: Activating the norms and habits of social connectedness. Communication Theory, 26(2), 128-149. https://doi.org/10.1111/comt.12090

Carrier, L. M., Rosen, L. D., Cheever, N. A. \& Lim, A. F. (2015). Causes, effects, and practicalities of everyday multitasking. Developmental Review, 35, 64-78. https://doi.org/10.1016/j.dr.2014.12.005

Carrier, L. M., Cheever, N. A., Rosen, L. D., Benitez, S. \& Chang, J. (2009). Multitasking across generations: Multitasking choices and difficulty ratings in three generations of Americans. Computers in Human Behavior, 25(2), 483-489. https://doi.org/10.1016/j.chb.2008.10.012

Carter, S., Greenberg, K. \& Walker, M. (2017). The impact of computer usage on academic performance: Evidence from a randomized trial at the United States Military Academy. Economics of Education Review, 56, 118-132. https://doi.org/10.1016/j.econedurev.2016.12.005

Chen, Y. F. \& Katz, J. E. (2009). Extending family to school life: College students' use of the mobile phone. International Journal of Human-Computer $\quad$ Studies, 67(2), 179-191. https://doi.org/10.1016/j.ijhcs.2008.09.002

Courage, M. L., Bakhtiar, A., Fitzpatrick, C., Kenny, S. \& Brandeau, K. (2015). Growing up multitasking: The costs and benefits for cognitive development. Developmental Review, 35, 5-41. https://doi.org/10.1016/j.dr.2014.12.002

Finkel, J. \& Kruger, D. J. (2012). Is cell phone use socially contagious? Human Ethology Bulletin, 27(1-2), 15-17.

Hammer, R., Ronen, M., Sharon, A., Lankry, T., Huberman, Y. \& Zamtsov, V. (2010). Mobile culture in college lectures: Instructors' and students' perspectives. Interdisciplinary Journal of E-Learning and Learning Objects, 6(1), 293-304. https://doi.org/10.28945/1316

Junco, R. \& Cotten, S. R. (2011). Perceived academic effects of instant messaging use. Computers \& Education, 56(2), 370-378. https://doi.org/10.1016/j.compedu.2010.08.020

Kruger, D. J., Juhasz, D., Saunders, C., Misevich, S., Duan, A., Heyblom, A. \& Phaneuf, C. (2018). Factors predicting observed cellphone use in a Midwestern USA university campus area. Human Ethology Bulletin, 33(2), 5-12. https://doi.org/10.22330/heb/332/005-012

Lampe, C., Wohn, D. Y., Vitak, J., Ellison, N. B. \& Wash, R. (2011). Student use of Facebook for organizing collaborative classroom activities. International Journal of Computer-Supported Collaborative Learning, 6(3), 329-347. https://doi.org/10.1007/s11412-011-9115-y

Lau, W. W. F. (2017). Effects of social media usage and social media multitasking on the academic performance of university students. Computers in Human Behavior, 68, 286-291.https://dx.doi.org/10.1016/j.chb.2016.11.043

Ling, R. (2012). Taken for grantedness: The embedding of mobile communication into society. "It is not your desire that decides": The reciprocal expectations of mobile telephony. MIT Press, 159-179. https://doi.org/10.7551/mitpress/8445.001.0001

Madge, C., Meek, J., Wellens, J. \& Hooley, T. (2009). Facebook, social integration and informal learning at university: 'It is more for socialising and talking to friends about work than for actually doing work'. Learning, media and technology, 34(2), 141-155. https://doi.org/10.1080/17439880902923606

Palmer, B., Boniek, S., Turner, E. \& Lovell, E. (2014). Undergraduates, technology, and social connections. College Student Journal, 48(2), 281-296.

Perry, S. D. \& Lee, K. C. (2007). Mobile phone text messaging overuse among developing world university students. Communication, 33(2), 63-79. https://doi.org/10.1080/02500160701685417

Roberts, J., Yaya, L. \& Manolis, C. (2014). The invisible addiction: Cell-phone activities and addiction among male and female college students. Journal of behavioral addictions, 3(4), 254-265. https://doi: 10.1556/JBA.3.2014.015

Rosen, L. D., Carrier, L. M. \& Cheever, N. A. (2013). Facebook and texting made me do it: Media-induced task-switching while studying. Computers in Human Behavior, 29(3), 948-958. https://doi.org/10.1016/j.chb.2012.12.001

Sana, F., Weston, T \& Cepeda, N.J. (2013) Laptop multitasking hinders classroom learning for both users and nearby peers. Computers \& Education, 62, 24-31. https://doi.org/10.1016/j.compedu.2012.10.003 
Schraw, G., Crippen, K. J. \& Hartley, K. (2006). Promoting self-regulation in science education: Metacognition as part of a broader perspective on learning. Research in Science Education, 36(1-2), 111-139. https://doi.org/10.1007/s11165-005-3917-8

Terry, C. A., Mishra, P. \& Roseth, C. J. (2016). Preference for multitasking, technological dependency, student metacognition \& pervasive technology use: An experimental intervention. Computers in Human Behavior, 65, 241-251. http://dx.doi.org/10.1016/j.chb.2016.08.009

Tindell, D. R. \& Bohlander, R. W. (2012). The use and abuse of cell phones and text messaging in the classroom: A survey of college students. College Teaching, 60(1), 1-9. https://doi.org/10.1080/87567555.2011.604802

Van der Schuur, W. A., Baumgartner, S. E., Sumter, S. R. \& Valkenburg, P. M. (2015). The consequences of media multitasking for youth: A review. Computers in Human Behavior, 53, 204-215. https://doi.org/10.1016/j.chb.2015.06.035

Wang, Z. \& Tchernev, J. M. (2012). The "myth" of media multitasking: Reciprocal dynamics of mediamultitasking, personal needs, and gratifications. Journal of Communication, 62(3), 493-513. https://doi.org/10.1111/j.1460-2466.2012.01641.x

Wood, E., Mirza, A. \& Shaw, L. (2018). Using technology to promote classroom instruction: assessing incidences of on-task and off-task multitasking and learning. Journal of Computing in Higher Education, 30(3), 553-571. https://doi.org/10.1007/s12528-018-9185-1

Wood, E., Zivcakova, L., Gentile, P., Archer, K., De Pasquale, D. \& Nosko, A. (2012). Examining the impact of off-task multi-tasking with technology on real-time classroom learning. Computers \& Education, 58(1), 365-374. https://doi.org/10.1016/j.compedu.2011.08.029

Woodcock, B., Middleton, A. \& Nortcliffe, A. (2012). Considering the Smartphone Learner: developing innovation to investigate the opportunities for students and their interest. Student Engagement and Experience Journal, l(1), 1-15. http://dx.doi.org/10.7190/seej.v1i1.38

Yang, C. C. (2018). Social media as more than a peer space: College freshmen encountering parents on Facebook. Journal of Adolescent Research, 33(4), 442-469. https://doi.org/10.1177/0743558416659750

\section{Note}

Note 1. Analyses indicated no differences in students' responses to the two types of messages sent. 